\title{
Variation in the Origin of Superior Thyroid Artery and it's Relation with External Laryngeal Nerve: A Cadaveric Study
}

\author{
AnujRam Sharma ${ }^{1}$ \\ ${ }^{1}$ Assistant Professor, Department of Anatomy, MuzaffarnagarMedical College, Opposite Behrajpurlndustrial Area, Muzaffarnagar UP, India.
}

Abstract

Introduction:The Thyroid gland is a highly vascular gland placed anteriorly in the neck, extending from the level of fifth cervical vertebra to first thoracic vertebra. The lobes of gland are conical. Their apices diverge laterally to the oblique line on the lamina of thyroid cartilage, and their bases are at the level of 4th or 5th tracheal ring. The relationship of the superior thyroid artery to the external laryngeal nerve is important to the surgeon during thyroid surgery. The artery and nerve are close to each other higher up but diverge near the gland. Thus in order to avoid injury to the external laryngeal nerve, the superior thyroid artery is ligated as near to the gland as possible. Subjects and Methods:This study was conducted on 50 cadavers of known age and sex in the dissection laboratory, department of anatomy. The cadavers were embalmed through carotid arterial perfusion or femoral arterial perfusion. Results:The site of the origin of the superior thyroid artery (STA) was evaluated as it arose from external carotid artery in 66\% cases, from carotid bifurcation in $33 \%$ cases and from common carotid artery in $1 \%$ cases. The site of the origin of the superior thyroid artery (STA) was evaluated as it arose from external carotid artery in $66 \%$ cases, from carotid bifurcation in 33\% cases and from common carotid artery in $1 \%$ cases. The evaluation of distance from upper pole of the thyroid gland to the level where External superior laryngeal nerve turns medially from Superior thyroid artery was found More than $1 \mathrm{~cm}$ in $73 \%$ cases \& Less than $1 \mathrm{~cm}$ in $27 \%$ cases. Conclusion:The relationship of superior thyroid artery to external superior laryngeal nerve is very important for surgeons during thyroid surgeries to avoid injuries to above nerves while ligating STA.

Keywords: Thyroid gland, superior thyroid artery (STA), Inferior thyroid artery (ITA), External laryngeal nerve, thyroid surgery, variation.

Corresponding Author:Dr. AnujRam Sharma, Assistant Professor, Department of Anatomy, Muzaffarnagar Medical College, Opposite Behrajpur Industrial Area, Muzaffarnagar UP, India

Received:January 2019

Accepted:February 2019

Introduction

The thyroid gland is a highly vascular gland placed anteriorly in the neck, extending from the level of fifth cervical vertebra to first thoracic vertebra. ${ }^{[1]}$ The lobes of gland are conical. Their apices diverge laterally to the oblique line on the lamina of thyroid cartilage, and their bases are at the level of 4 th or 5 th tracheal ring. ${ }^{[2]}$ The gland is supplied by the superior thyroid artery (STA) and inferior thyroid artery (ITA), and/sometimes the thyroideama artery which is a branch from brachiocephalic trunk or arch of aorta.

The superior thyroid artery (STA) is a branch arising from front of external carotid artery, gives glandular branches which on reaching the superior pole of the gland divide into anterior and posterior branches. ${ }^{[3]}$ The anterior branch accompanies the medial border of lateral lobe and anastomoses with its fellow of opposite side along the upper border of the isthmus of the gland. ${ }^{[4]}$ The posterior branch passes downward along the posterior border of lateral lobe and anastomoses with the ascending branch of inferior thyroid artery. The superior thyroid artery supplies the capsule and the connective tissue of the gland. ${ }^{[5]}$

The inferior thyroid artery a branch from thyrocervical trunk penetrates the deep surface of the gland and supplies the parenchyma of the gland. ${ }^{[-7]}$ The gland is also supplied by numerous accessory thyroid arteries and occasionally by arteriathyroideaima.

The relationship of the superior thyroid artery to the external laryngeal nerve is important to the surgeon during thyroid surgery ${ }^{[8]}$ The artery and nerve are close to each other higher up but diverge near the gland. Thus in order to avoid injury to the external laryngeal nerve, the superior thyroid artery is ligated as near to the gland as possible. The STA is frequently used as a recipient vessel for microvascular free tissue transfer in head and neck surgery, for selective embolization of thyroid and head and neck tumors, and as a landmark for identifying the external branch of the superior laryngeal nerve in thyroid surgery. ${ }^{[9]}$

Surgical procedures that involve the STA include radical neck dissection, cricothyroidotomy, thyroidectomy, reconstruction of an aneurysm, carotid endarterectomy, treatments for cancer, diagnostic and therapeutic 
catheterization, and plastic surgery. $\cdot{ }^{[9-11]}$ Additionally, a detailed knowledge of these explicit arterial variations is extremely helpful while carrying out procedures like carotid angiographies, neck dissections and thyroid resections. ${ }^{[12]}$ The implications of arterial variations of thyroid gland may be important for academic and clinical purposes. ${ }^{[13]}$ This study was undertaken in an attempt to know the relative frequency of variations in arterial pattern and to compare with similar work done by others.

As is true of most vascular arrangements, the origin, thickness, driving patterns, and distribution patterns of the STA differ among individuals. Most of the studies of the STA have focused on the possible variations in its origin. In general, textbooks state that it arises from the ECA as a main branch, but Gupta et al. ${ }^{[10]}$ reported that it can originate from the ECA, from the bifurcation of the common carotid artery (CCA), or from the CCA. ${ }^{[9,11]}$

\section{Subjects and Methods}

This study was conducted on 50 cadavers of known age and sex in the dissection laboratory, department of anatomy in Muzaffarnagar Medical College, Uttar Pradesh. The cadavers were embalmed through carotid arterial perfusion or femoral arterial perfusion

\section{Dissection Method}

"According to Cunningham's Manual of Practical Anatomy, Fifteenth edition". The study involved 50 cadavers, in which arterial pattern of thyroid gland was observed bilaterally. The body was in supine position with neck slightly extended. A skin incision made from chin to sternum in midline, and the flap of skin reflected inferolaterally and platysma reflected upward. The fat and fascia removed from the margins of the sternocleidomastoid. Now the sternocleidomastoid retracted and the deep fascia removed from the anterior belly of diagastric to expose the infrahyoid muscles. Fat and fascia removed from the area between the posterior belly of diagastric and the superior belly of omohyoid to expose the carotid triangle. This exposed common carotid and internal carotid arteries medial to it and the external carotid artery anteromedial to the internal carotid artery. Exposed the External carotid artery and its branches. The Superior thyroid artery was the lowest branch in the triangle. The data collected during dissection on both sides includes the site of origin of superior thyroid artery (From External carotid artery/Common carotid artery/Common carotid artery bifurcation); the level of the origin of the superior thyroid artery in relation to upper border of lamina of thyroid cartilage (Above the lamina/at the lamina /below the lamina); and Relation of External superior laryngeal nerve to the superior thyroid Artery i.e. Distance from upper pole of the thyroid gland to the level. External superior laryngeal nerve turns medially from Superior thyroid artery was measured using digital vernier caliper.

\section{Results}

Table 1: Site of the origin of the superior thyroid artery (STA)

\begin{tabular}{|l|l|l|l|}
\hline $\begin{array}{l}\text { Site of origin of } \\
\text { STA }\end{array}$ & $\begin{array}{l}\text { Right side } \\
(\mathbf{n = 5 0 )}(\mathbf{\%})\end{array}$ & $\begin{array}{l}\text { Left side } \\
(\mathbf{n = 5 0 )}(\mathbf{\% )})\end{array}$ & $\begin{array}{l}\text { Total } \\
(\mathbf{n = 1 0 0 )} \\
(\mathbf{\%})\end{array}$ \\
\hline $\begin{array}{l}\text { External Carotid } \\
\text { Artery }\end{array}$ & $31(62)$ & $35(70)$ & $66(66)$ \\
\hline $\begin{array}{l}\text { Common Carotid } \\
\text { Bifurcation }\end{array}$ & $18(36)$ & $15(30)$ & $33(33)$ \\
\hline $\begin{array}{l}\text { Common Carotid } \\
\text { Artery }\end{array}$ & $01(2)$ & - & $01(01)$ \\
\hline
\end{tabular}

The site of the origin of the superior thyroid artery (STA) was evaluated as it arose from external carotid artery in $66 \%$ cases, from carotid bifurcation in $33 \%$ cases and from common carotid artery in $1 \%$ cases. [Table 1]

The level of the origin of the superior thyroid artery in relation to upper border of thyroid cartilage, in $87 \%$ cases level of the origin was above the thyroid cartilage and in $13 \%$ cases level of the origin was at the same level of thyroid cartilage. [Table 2, Figure 1]

Table2: Level of the origin of the superior thyroid artery in relation to upper border of thyroid cartilage

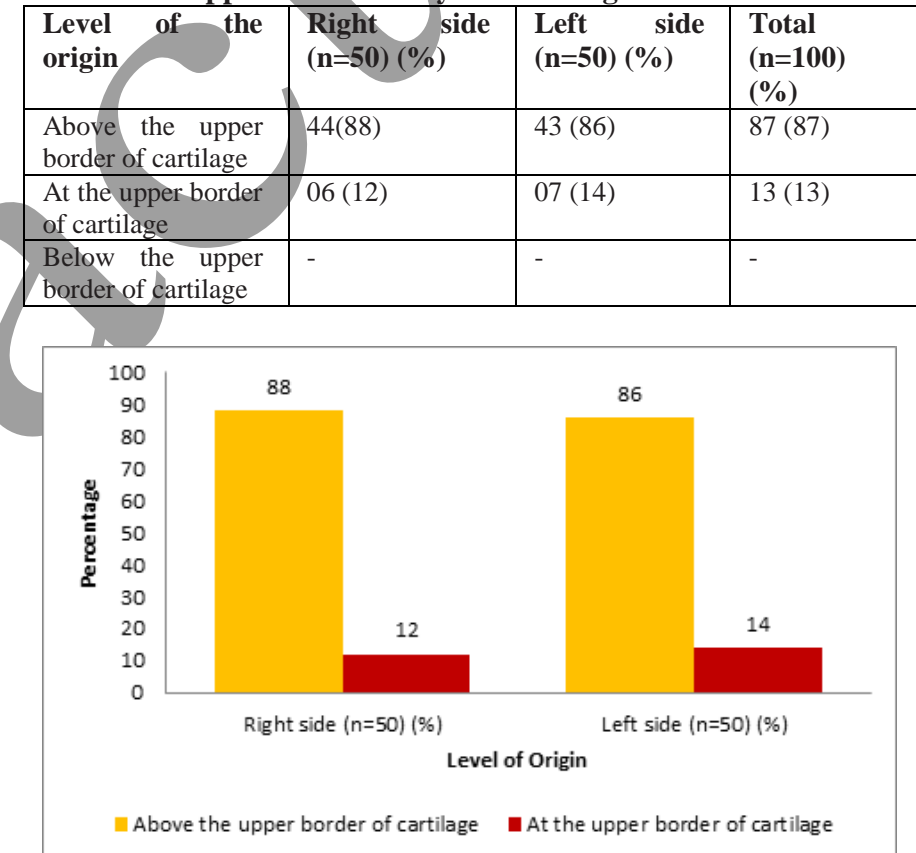

Figure 1: Level of the origin of the superior thyroid artery in relation to upper border of thyroid cartilage

Table3: Distance from upper pole of the thyroid gland to the level where external laryngeal nerve turn medially from STA

\begin{tabular}{|l|l|l|l|l|}
\hline Distance & $\begin{array}{l}\text { Right } \\
\text { side } \\
(\mathbf{n = 3 3 )} \\
(\mathbf{\%})\end{array}$ & $\begin{array}{l}\text { Left side } \\
(\mathbf{n = 3 3 )} \\
(\mathbf{\%})\end{array}$ & $\begin{array}{l}\text { Total } \\
(\mathbf{n = 6 6 )} \\
(\mathbf{\%})\end{array}$ & $\begin{array}{l}\text { P } \\
\text { value }\end{array}$ \\
\hline More than $1 \mathrm{~cm}$ & $38(76)$ & $35(70)$ & $73(73)$ & 0.005 \\
\hline Less than $1 \mathrm{~cm}$ & $12(24)$ & $15(30)$ & $27(27)$ & \\
\hline
\end{tabular}




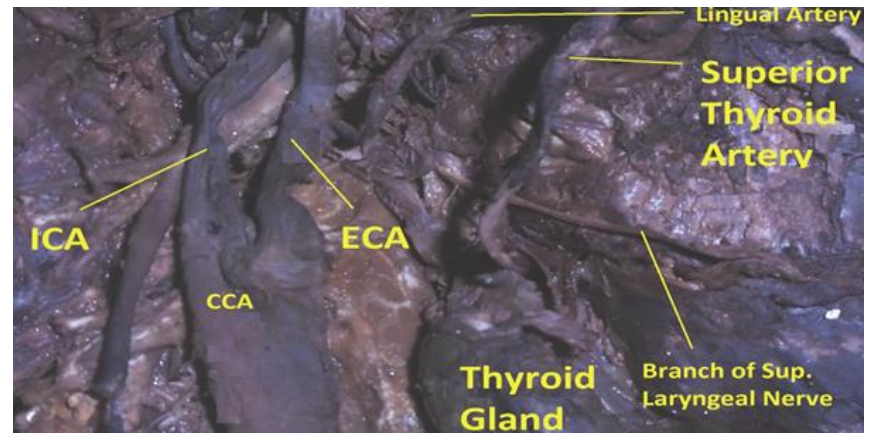

Figure 2: Variations of the origin of superior thyroid artery and its relationship with superior laryngeal nerve

The evaluation of distance from upper pole of the thyroid gland to the level where External superior laryngeal nerve turns medially from Superior thyroid artery was found more than $1 \mathrm{~cm}$ in $73 \%$ cases \& Less than $1 \mathrm{~cm}$ in $27 \%$ cases [Table 3\& 4] shows comparison of site of origin of STA in various studies. [Figure 2] Shows the Variations of the origin of superior thyroid artery and its relationship with the external branch of superior laryngeal nerve.

Table 4 shows comparison of site of origin of STA in various studies

\begin{tabular}{|c|c|}
\hline Site \& Prevalence & Quoting author \\
\hline \multicolumn{2}{|c|}{ External Carotid Artery } \\
\hline $66 \%$ & Present study \\
\hline $30 \%$ & Lucev $^{[14]}$ \\
\hline $68 \%$ & Banna M. et al, ${ }^{[15]}$ \\
\hline $59 \%$ & TakkallapalliAnitha et al, ${ }^{[16]}$ \\
\hline \multicolumn{2}{|c|}{ Common Carotid Artery } \\
\hline $1 \%$ & Present study \\
\hline $47.50 \%$ & Lucev $^{[14]}$ \\
\hline $10 \%$ & Banna M. et al, ${ }^{[15]}$ \\
\hline $21 \%$ & TakkallapalliAnitha et al \\
\hline \multicolumn{2}{|l|}{ Carotid Bifurcation } \\
\hline $33 \%$ & Present study \\
\hline $22.50 \%$ & Lucev, ${ }^{[14]}$ \\
\hline $22 \%$ & Banna M. et $\mathrm{al}^{[15]}$ \\
\hline $19 \%$ & TakkallapalliAnithà et al, ${ }^{[16]}$ \\
\hline
\end{tabular}

Thyroid gland is the largest endocrine gland in the body and plays an important role in the maintenance of the basal metabolic rate and is a highly vascular endocrine gland. Generally, the common carotid artery does not give any branches except external and internal carotid arteries.08Superior thyroid artery commonly arises from the external carotid artery. Faller and Sharrer, ${ }^{[17]}$ reported that the superior thyroid artery may arise from the common carotid artery in $18 \%$ of cadavers, from external carotid artery in $36 \%$ of cadavers or from the point of division of common carotid artery in $36 \%$ of cases. Chandralekha and Cooper, ${ }^{[18]}$ studied the patterns of origin of superior thyroid arteries in 40 south Indian cadavers and it was observed that in $30 \%$ cases the superior thyroid artery arose from common carotid. In present study, the superior thyroid artery arises from external carotid artery in $66 \%$ cases, from carotid bifurcation in $33 \%$ cases and from common carotid artery in $1 \%$ cases. The level of the origin of the superior thyroid artery in relation to upper border of thyroid cartilage is important and it has been reported in previous studies. A study conducted by TakkallapalliAnithaet $a l,{ }^{[16]}$ found that the STA arises below the level of upper border of thyroid cartilage (56\% on right, $66 \%$ on left side).The external laryngeal nerve runs parallel to superior thyroid artery and later turns medially from the artery either above or below the upper pole of the thyroid gland. The distance between upper pole of thyroid gland and medial turning of external laryngeal nerve has been reported in previous studies. ${ }^{[19-21]}$

The relationship of superior thyroid artery with the external laryngeal nerve was observed in all the cases. It was observed that in all the cases, the the STAs were lying anteriorly and laterally to the ELNs at superior pole of the thyroid gland. Most of the anatomical textbooks have described the usual relation between the STAs to be as anterior and lateral to ELNs at the upper pole of the gland. ${ }^{[22]}$ A study conducted by Magoma et al19 found that the external laryngeal nerve crossed the superior thyroid artery within $1 \mathrm{~cm}$ above the upper pole of the thyroid gland in $25 \%$ of cases and more than $1 \mathrm{~cm}$ in $75 \%$ of cases. The similar result was found in our study the external laryngeal nerve crossed the superior thyroid artery within $1 \mathrm{~cm}$ above the upper pole of the thyroid gland in $27 \%$ of cases and more than $1 \mathrm{~cm}$ in $73 \%$ of cases.

\section{Conclusion}

Ever since the thyroid gland has been discovered, it has been studied extensively by the anatomists, physiologists, pathologists, physicians and surgeons. Thyroid arteries are of much importance in providing blood supply to the gland. These arterial variations related to the thyroid gland is of immense importance in formulating planned surgical approaches to the thyroid gland and in alerting the surgeons to avoid inadvertent injuries to the vital anatomical structures in this area. The relationship of superior thyroid artery to external superior laryngeal nerve is very important for surgeons during thyroid surgeries to avoid injuries to above nerves while ligating STA.

\section{References}

1. Standring S, Herold E, Healy JC, Johnson D, Williams A. Gray's Anatomy. 39th Ed. Elsevier, Churchill Livingstone 2005; p560-4.

2. Moore KL, Dalley AF. Clinical oriented Anatomy. 3rd ed, Lippincott Williums -Wilkins. 2006; 1083-1085.

3. Sindel M, O O, G A, O K, T S. Anatomical variation in the origin of superior thyroid artery Int J Anat Var. 2017;10(S1):56-7

4. Takkallapalli A, Dombe D, Krishnamurthy A, Kalbande S. Clinically relevant variations of the superior thyroid artery: An anatomical guide for neck surgeries. Int $\mathrm{J}$ Pharm Biomed Sci 2011;2:514.

5. Joshi A, Gupta S, Vaniya VH. Anatomical variation in the origin of superior thyroid artery and it's relation with external laryngeal nerve. National Journal of Medical Research. 2014;4(2):138-41.

6. The thyroid, thymus and the parathyroid gland. In: Decker GA, Plessis DJ, editors. Lee McGregor's Synopsis of Surgical Anatomy. 12th ed. Bombay: Varghese Publishing House; 1986. p. 198207.

7. Hollinshead WH. The Head and Neck. Anatomy for Surgeons. 3rd ed., Vol. 1. Philadelphia: Harper and Row; 1982. 
8. Dutta AK. Essentials of human anatomy. 2nd Ed. Calcutta, Current Books International 1994; 127-132.

9. Vazquez T, Cobiella R, Maranillo E, Valderrama FJ, McHanwell S, Parkin I, Sanudo JR. Anatomical variations of the superior thyroid and superior laryngeal arteries. Head Neck 2009; 31: 1078-85.

10. Gupta P, Bhalla AS, Thulkar S, Kumar A, Mohanti BK, Thakar A, Sharma A. Variations in superior thyroid artery: a selective angiographic study. Indian J Radiol Imaging 2014;24:66-71.

11. Cha YH, Moon S-Y, Jehoon O, Tansatit T, Yang H-M. Anatomy of the external branch of the superior laryngeal nerve in Asian population. Scientific Reports. 2017;7

12. Yilmaz E, Celik HH, Durgun B, Atasever A, Ilgi S. Arteriathyroideaima arising from brachiocephalic trunk with bilateral absence of inferior thyroid arteries: A case report. SurgRadiolAnat 1993; 15:197-9.

13. Dessie MA, Variations of the origin of superior thyroid artery and its relationship with the external branch of superior laryngeal nerve. PLOS ONE 2018, 13(5): e0197075.

14. Lucev-N, Babinac D, Maric I, Drescik I, Variations of the great arteries in the carotid triangle. Otolaryngol Head and Neck Surgery 2000, 122, 590-591

15. Banna M, Lasjaunias P. The arteries of the lingual thyroid: angiographic findings and anatomic variations. Am J Neuro-radiol
1990, 11, 730-732.

16. TakkallapalliAnitha, DattatrayDombe, Krishnamurthy Asha, Sanjay Kalbande, Clinically relevant variations of the superior thyroid artery: An anatomic guide for neck surgeries, Int J Pharm Biomed Sci 2011, 2(2), 51-54.

17. Faller A ,Sharrer O. Uber die Variabilitat des arteriathyroidea. Acta Anat.1947; 4: 117-119.

18. Chandralekha G, Cooper MM. Origin of superior thyroid artery. J AnatSoc India 1977; 26: 35

19. Magoma, Georgina; Saidi, Hassan; Kaisha, Wyckliffe Relation of the external laryngeal nerve to superior thyroid artery in an african population :8080/xmlui/handle/123456 789/112192012

20. Naidoo D, Boon JM, Mieny CJ, Becker PJ, van Schoor AN. Relation of the external branch of the superior laryngeal nerve to the superior pole of the thyroid gland: an anatomical study. Clin Anat. $2007 \mathrm{Jul} ; 20(5): 516-20$

21. Botelho JB, Cardoso Neto J, DosAnjos GS \& et al. Relation between the external branch of the superior laryngeal nerve and the superior thyroid artery: a study in 101 nerves. Pubmed 2009 jul;36(3):187-92

22. Sinnatamby CS. Lasts Anatomy. Regional And Applied.11th Ed. Churchill Livingstone; 2006.p 351- 2

Copyright: (c) the author(s), publisher. Academia Anatomica Internationalis an Official Publication of "Society for Health Care \& Research Development". It is an open-access article distributed under the terms of the Creative Commons Attribution Non-Commercial License, which permits unrestricted non-commercial use, distribution, and reproduction in any medium, provided the original work is properly cited.

How to cite this article: Sharma AR. Variation in the Origin of Superior Thyroid Artery and it's Relation with External Laryngeal Nerve: A Cadaveric Study. Acad. Anat. Int. 2019;5(1):6-9.

DOI: dx.doi.org/10.21276/aanat.2019.5.1.2

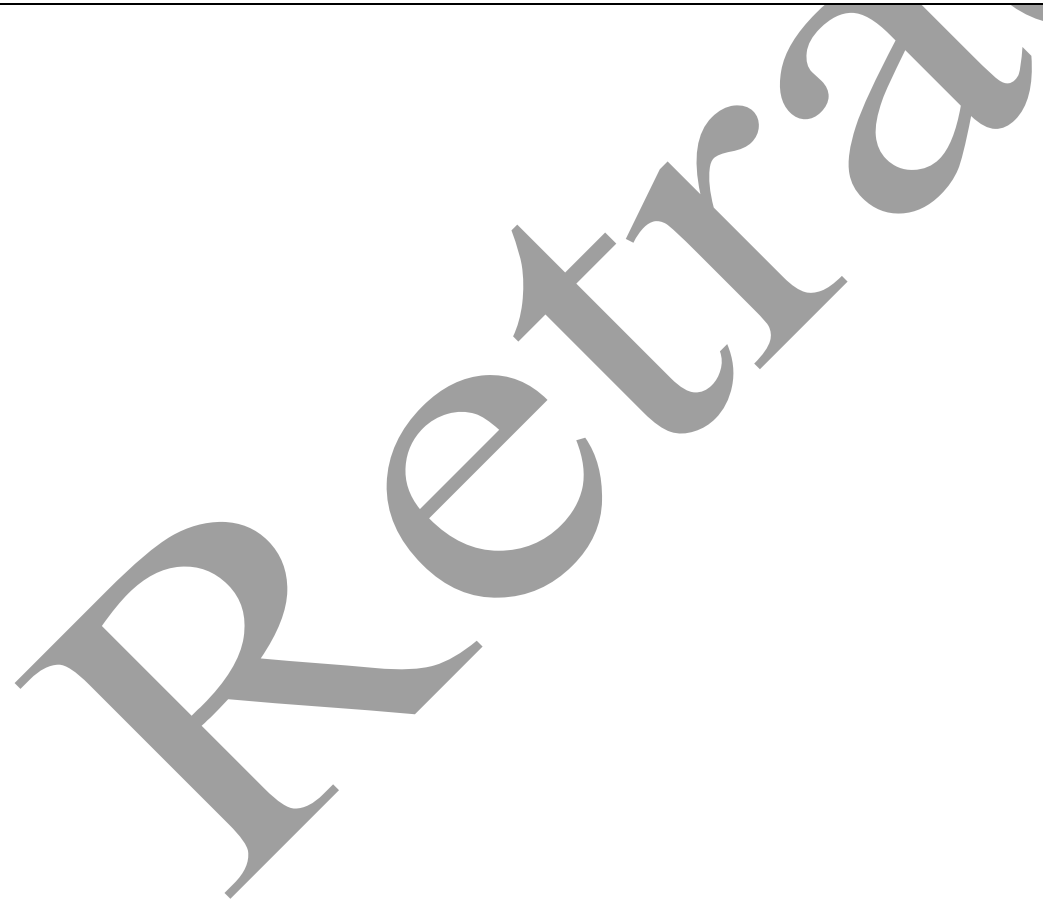

